\title{
Correction to: Conservation Biology
}

\author{
Fred Van Dyke and Rachel L. Lamb
}

\section{Correction to: F. Van Dyke, R. L. Lamb, Conservation Biology, https://doi.org/10.1007/978-3-030-39534-6}

An earlier version of the book has been published with certain errors. This has now been corrected and the following are the corrections:

- The copyright holder of the previous edition has been corrected.

- The scientific name "Cervus elaphus" has been corrected to "Cervus canadensis" throughout the book.

- The scientific name "Picoides borealis" has been corrected to "Leuconotopicus borealis" throughout the book.

Chapter 1: The History and Distinctions of Conservation Biology

- The sentence "We have already seen how insensitivity to human presence in any. .." on page no. 30 has been corrected as follows: "We have already seen how insensitivity to human presence in any landscape leads to both social injustice and environmental degradation, and more examples will follow in subsequent chapters, especially those concerned with anthropogenic influence (Chap. 3), climate change (Chap. 4), conservation values and ethics (Chap. 10) and conservation economics and sustainable development (Chap. 11)."

Chapter 7: The Conservation of Terrestrial Habitat and Landscape

- The correct version of the caption for Table 7.2 on page no. 269 is as follows: "In this matrix, the total number (tally) of cells initially classified as "aspen" at time $t$ is 20. In 14 of the 20 cells "aspen" has been replaced by "lodgepole" at time $t+1$, while 2 remain "aspen," 2 succeed to "spruce" and 2 become "meadow." The row total for aspen is then $2+14+2+0+2 / 20$ and the aspen-to-lodgepole transition is 14/20 or 0.7. Thus, 0.7 is the value of pij (paspen to lodgepole) in this transition matrix, the probability that aspen will be replaced by lodgepole over the observed time span. The diagonal elements in the matrix represent the proportion of cells of each cover type that did not change (stasis rates). Design by F. Van Dyke".

Chapter 11: Conservation Economics and Sustainable Development

- The numbered list of points within the Overview box in page 449, which were not capitalized earlier, has been corrected now.

The updated version of the book can be found at https://doi.org/10.1007/978-3-030-39534-6 
- The sentence "The re-introduction of the gray wolf..." on page no. 461 has been corrected as follows: "The re-introduction of the gray wolf (Canis lupus) in Yellowstone National Park in the 1990s (more in Chap. 12) could not have proceeded without a compensation program established by Defenders of Wildlife, the Bailey Wildlife Foundation Wolf Compensation Trust, to reimburse ranchers outside the park for livestock losses caused by wolves. In the same way, to get farmers in Wisconsin (USA) to accept legal protection for wolves, compensation had to be paid for losses of farm animals from wolf predation in that state (Treves et al. 2009, Fig. 11.8)."

Chapter 13: Conservation as Vocation

- The sentence "Women conference organizers provided a platform for other..." on page no. 560 has been corrected as follows: "Women conference organizers provided a platform for other women to highlight their work which, for multiple reasons, was more accessible to women than symposia organized by male leaders." 